\section{LA-UR-Y -}

Approved for public release; distribution is unlimited.

\title{
$8-1.182$
}

TITLE: LCS/CINDER '90 ACCELERATOR TUNNEL ACTIVATION CALCULATIONS FOR THE APT 1700-MeV ACCELERATOR TUNNEL

$$
\text { CONF-98040Z-- }
$$

AUTHOR(S):

J. D. Court, X-CI

E.C. Snow, X-CI

W.B. Wilson, T-2

E.J. Pitcher, APT-TPO

Los Alamos National Laboratory, an affirmative action/equal opportunity employer, is operated by the University of California for the U.S. Department of Energy under contract W-7405-ENG-36. By acceptance of this article, the publisher recognizes that the U.S. Government retains a nonexclusive, royalty-free license to publish or reproduce the published form of this contribution, or to allow others to do so, for U.S. Government purposes. The Los Alamos National Laboratory requests that the publisher identify this article as work performed under the auspices of the U.S. Department of Energy. The Los Alamos National Laboratory strongly supports academic freedom and a researcher's right to publish; as an institution, however, the Laboratory does not endorse the viewpoint of a publication or guarantee its technical correctness. 


\section{DISCLAIMER}

This report was prepared as an account of work sponsored by an agency of the United States Government. Neither the United States Government nor any agency thereof, nor any of their employees, makes any warranty, express or implied, or assumes any legal liability or responsibility for the accuracy, completeness, or usefulness of any information, apparatus, product, or process disclosed, or represents that its use would not infringe privately owned rights. Reference herein to any specific commercial product, process, or service by trade name, trademark, manufacturer, or otherwise does not necessarily constitute or imply its endorsement, recommendation, or favoring by the United States Government or any agency thereof. The views and opinions of authors expressed herein do not necessarily state or reflect those of the United States Government or any agency thereof. 


\section{DISCLAIMER}

Portions of this document may be illegible in electronic image products. Images are produced from the best available original document. 


\title{
LCS'/CINDER'90 ACCELERATOR TUNNEL ACTIVATION CALCULATIONS FOR THE APT 1700-MeV ACCELERATOR TUNNEL
}

\author{
John D. Court, Edward C. Snow, William B. Wilson, and Eric J. Pitcher
}

\begin{abstract}
Calculations have been done to determine the amount of activation in the linac components and tunnel air for the Accelerator Production of Tritium 1700-MeV super-conducting linac. Proton transport is accomplished through the use of the LAHET Code System. Particle production and depletion from proton and high-energy neutron reactions, calculated in LAHET, as well as low-energy neutron fluxes calculated by MCNP, are passed to the radionuclide production code CINDER'90 to determine the source terms at various times after irradiation. The upper limit on total air activation based on conservative assumptions, for the entire tunnel air volume, was found to be $4.77 \mathrm{Ci}$ after a nine-month irradiation. This is reduced to $0.09 \mathrm{Ci}$ after a 10-hour cooling off period. The total activation for the full $1-\mathrm{km}$ of beamline components was found to be less than $4 \mathrm{kCi}$, with the half-lives of the highest contributors ranging from 12 years to 2 minutes. This beamline component activation calculation was done for an irradiation time of 40 years, which is the anticipated lifetime of the super-conducting linac.
\end{abstract}

\section{INTRODUCTION}

The proposed Accelerator Production of Tritium (APT) accelerator will be a 1700-MeV super-conducting linac, approximately $1-\mathrm{km}$ in length. Calculations have been done to determine tunnel component activation and radionuclide inventories in support of the APT Environmental Impact Statement (EIS).

The calculations were done using the LAHET $^{\mathrm{T}}$ Code System $(\mathrm{LCS})^{1}$ to determine nuclide production rates and flux levels in the accelerator beamline components and tunnel air. These flux values were then passed to the CINDER' $90^{2.3}$ code to determine activation, decay, and radionuclide inventories. Air activation was calculated after a nine-month irradiation, as well as after several decay periods. This calculation provides a source term for the EIS loss of confinement accident (tunnel purge of normally activated air without delay). The beamline component activation calculation provides radionuclide inventories for the shutdown and decommissioning of the accelerator after the proposed 40-year operational lifetime. This source term is also used for the EIS.

A detailed model of the accelerator beamline and tunnel was constructed for Monte Carlo calculations using the LCS. LAHET transports charged particles, and neutrons down to a cutoff energy of $20 \mathrm{MeV}$. All neutrons $20 \mathrm{MeV}$ and below are then written to a source file for use in MCNPTM4. The flux values in regions of interest are then tallied and used by CINDER' 90 to determine radioisotope production and decay. The calculated values were then scaled to assume $10-\mathrm{nA} / \mathrm{m}$ beam spill over the full $1-\mathrm{km}$ linac length. Fourteen different material regions were used to identify the nuclides with the highest activities after irradiation.

\section{LAHET CODE SYSTEM}

The LAHET Code System is a descendent of the HETC code $^{5}$ originally developed at Oak Ridge National Laboratory (ORNL) in the 1960's. Unless otherwise noted, the default settings, as reported in the LCS user's guide, 'were used in the LAHET calculations in this report. The exceptions are shown in Table 1. In LAHET, with these settings, the Bertini $^{6}$ model is used to simulate the intranuclear cascade phase. The multi-stage pre-equilibrium model ${ }^{7}$ is then invoked prior to the evaporation phase. The Dresner ${ }^{8}$ evaporation model is used for the evaporation of nucleons from the excited nucleus, except for the case of light nuclei, when it is replaced by the Fermi ${ }^{9}$ breakup model. LAHET version $2.83^{10}$ was used, including the new neutron and proton elastic scattering treatment.

\footnotetext{
${ }^{\text {mm }}$ LAHET and MCNP are trademarks of the Regents of the University of California, Los Alamos National Laboratory.
} 
Table 1. Non-default physics model settings in the LAHET input deck.

\begin{tabular}{|c|c|l|l|}
\hline Line & Record & \multicolumn{1}{|c|}{ Setting } & \multicolumn{1}{|c|}{ Description } \\
\hline 4 & 12 & IPREQ = 1 & $\begin{array}{l}\text { use pre-equilibrium model following the intranuclear cascade } \\
\text { Default: no pre-equilibrium model will be used }\end{array}$ \\
\hline 5 & 1 & NBERTP = -1 & $\begin{array}{l}\text { nucleon-pion-muon transport } \\
\text { Default: nucleon-pion transport only }\end{array}$ \\
\hline 6 & 1 & NSPRED = -5 & $\begin{array}{l}\text { step size for the multiple scattering treatment is reduced by a factor of 1/5 of the default for } \\
\text { both primary and secondary particles } \\
\text { Default: calculate multiple scattering for primary charged particles }\end{array}$ \\
\hline 6 & 4 & N1COL =1 & $\begin{array}{l}\text { compute cascade histories only through the second generation; } \\
\text { Default: compute all generations }\end{array}$ \\
\hline
\end{tabular}

\section{CINDER'90"}

CINDER'90 is a neutron transmutation code evolved from earlier versions of CINDER ${ }^{11,12,13}$ and $R E A C,{ }^{14}$ using the algorithm of CINDER with modifications to accommodate the input of additional constant destruction and production rates associated with reactions outside of the code's particle or energy domain. In conjunction with other codes simulating the radiation environment, CINDER' 90 has been used to describe nuclide inventories in a variety of applications. With the addition of coding and data to describe transmutation of higher- $\mathrm{Z}$ nuclides, including the spontaneous fission (SF) and neutron-induced fission $(n, f)$ of actinides, the range of applications is greatly extended. The library of nuclear data, constantly growing in breath and quality with international cooperation, now describes 3400 nuclides in the range $1 \leq Z \leq 103$.

CINDER is used to track, for each nuclide ( $\mathrm{Z}, \mathrm{A}$, and state), all transmutation paths (decay and neutron reactions) producing product nuclides differing from the original. It uses Markovian chains to determine temporal densities of nuclides in a neutron environment, solving for independent contributions to atom densities in each of a number of nuclide chains.

\section{LCS MODEL}

A detailed model of the accelerator beamline tunnel was developed. An elevation view of the tunnel is shown in Figure 1. The tunnel is encased by $1-\mathrm{m}$ thick concrete walls and is covered above by a dirt berm. Also shown are the klystron galleries and the aluminum waveguide structures present in the tunnel. The waveguide penetration from the tunnel to the klystron gallery basement was modeled in one module only, and was used in other calculations done for neutron streaming.

In each linac beamline module, the cryostat vacuum vessels containing the magnets and accelerator cavities were modeled in detail. One such module is shown in Figure 2. Each module contains five B82 $(\beta=0.82)$ magnets composed of iron, stainless steel, and copper. Also shown in Figure 2 are the four super-conducting accelerator cavities, composed of SS-316 stainless, niobium, and liquefied helium. Within the cryostat vacuum vessel, which has a wall thickness of $3 / 8^{\prime \prime}$ stainless steel, is a $1 / 4$ " copper heat shield. There is a $1 / 8$ " stainless steel beam tube that passes through the center of the magnets and surrounds the accelerator cavities.

Figure 3 gives additional detail to the accelerator beamline model. Shown in Figure 3 is the water load above the cryostat vessel, three water pipes, and six steel rods that represent part of the support structure of the wave guide assembly. This is a geometry slice through the center of a B82 magnet and two support legs. Also shown are three pipes within the cryostat vessel containing helium. The larger diameter pipe contains a 50-50 mixture of liquid and gaseous helium. The smaller two pipes contain liquid helium, and gaseous helium, respectively. The ring immediately surrounding these is the copper heat shield.

This module was then repeated to construct the accelerator tunnel model. Eight modules were used in the calculation. The eight modules are shown in Figure 4. Each module is $10.16 \mathrm{~m}$ in length. The total length of the model used was approximately $81 \mathrm{~m}$. The results from the calculation were then scaled to the $1-\mathrm{km}$ actual tunnel length, which yields a conservative estimate of radionuclide production over the accelerator tunnel because a $1700-\mathrm{MeV}$ beam energy

\footnotetext{
${ }^{a}$ For a more detailed discussion of CINDER'90, consult reference (3).
} 
is used in the calculation. In reality, the beam energy is $1700 \mathrm{MeV}$ only at the end of the $1-\mathrm{km}$ path. The beam is transported in the positive z-direction, entering module 7 first, then $6,5,4$, etc. To eliminate end effects, only modules 2,3 , and 4 were used for tallying purposes.

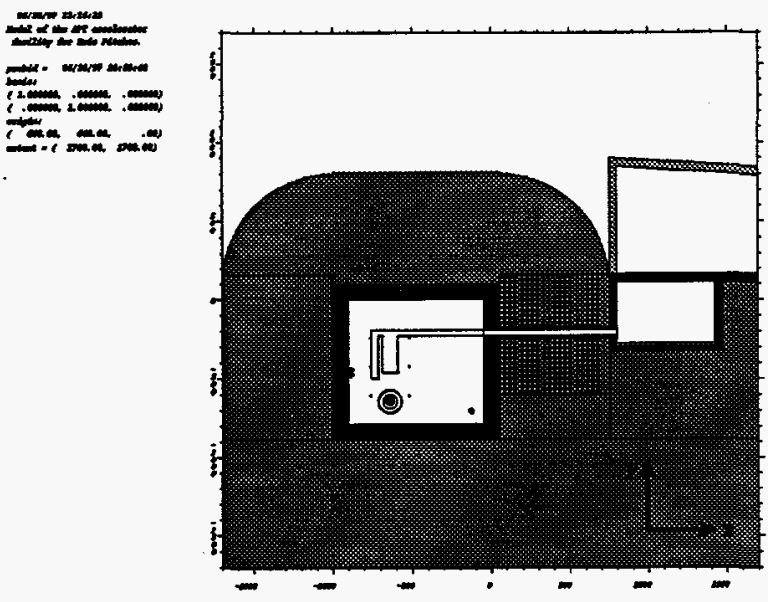

Figure 1. Elevation view of the MCNP geometry model.

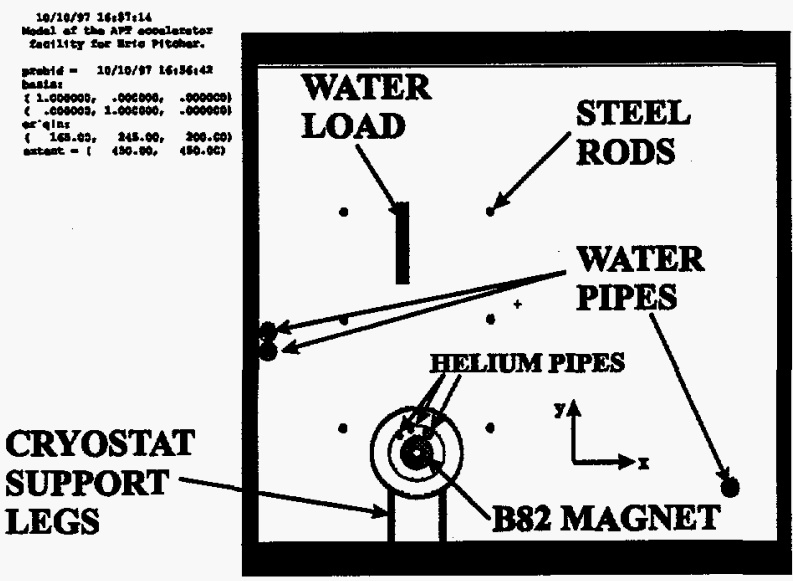

Figure 3. Detail of inner-tunnel components.

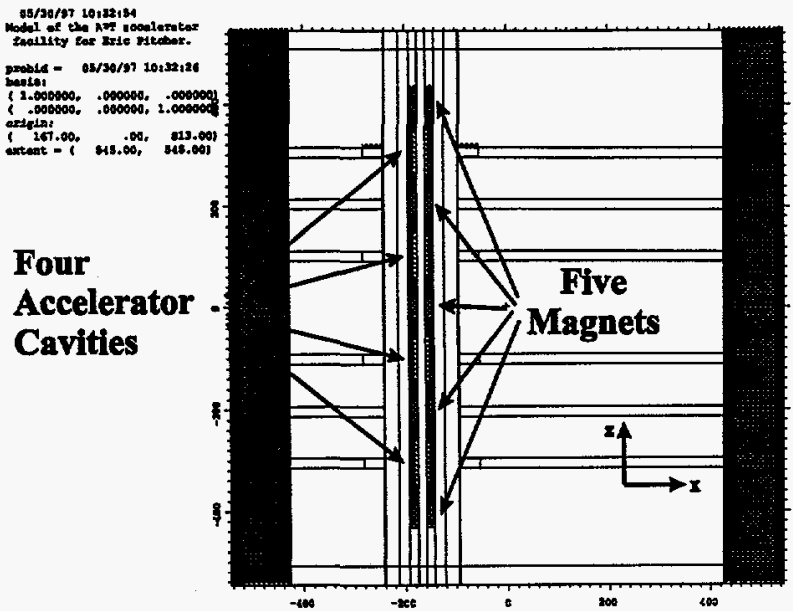

Figure 2. MCNP geometry plot of one accelerator beamline module.

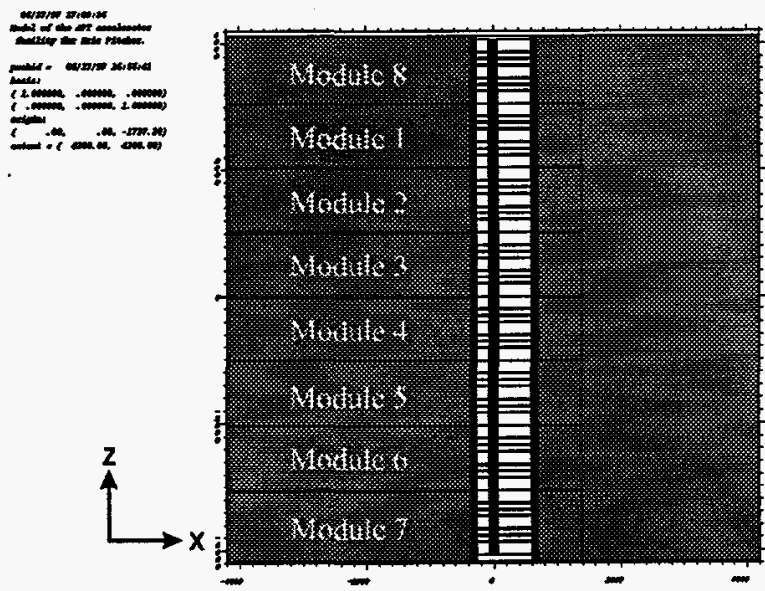

Figure 4. MCNP geometry plot of the LCS model showing the 8 modules. Each module is $10.16 \mathrm{~m}$ long.

\section{CAlCulation}

The CINDER'90 activation calculation is independent of the problem geometry. CINDER' 90 only requires the volume of material, its density and cross sections, and the flux values for that volume of material. This is accomplished by dividing the model into separate regions containing different materials and computing the flux in those regions. Then those fluxes and volumes can be passed for the activation/decay calculations. Table 2 shows the thirteen regions in the model for which activation calculations were done in CINDER'90. By convention, the regions are identified by the MCNP tally number of the flux tally in that region. Also included in the table are the material numbers associated with the region and a description of the type of component(s) contained in the region. These regions encompass all materials interior to the accelerator tunnel in modules 2,3 , and 4 . These are the modules in which the flux tallies have been computed. The locations of these modules were chosen to eliminate the end effects present in the truncated model of the 1$\mathrm{km}$ long accelerator tunnel. 
CINDER'90 receives flux values from MCNP. Both LAHET and MCNP use the same input geometries for their respective calculations. LAHET computes, and passes to CINDER' 90 , the spallation product inventories from spallation events occurring in the regions of interest, the production of nuclides from neutron and proton induced reactions, as well as the depletion rate caused by all charged particle reactions and neutron induced reactions. All charged particle transport is done in LAHET, as well as neutron transport of all neutrons above $20 \mathrm{MeV}$. LAHET first starts protons along a cylindrical surface located just inside the stainless-steel beam tube. This proton source consists of a cylinder of radius $7.95 \mathrm{~cm}$, stretching from $\mathrm{z}=-5898 \mathrm{~cm}$ to $\mathrm{z}=2395 \mathrm{~cm}$, with protons launched in the positive z-direction at an angle of $1^{\circ}$ with respect to the positive $\mathrm{z}$-axis. These protons undergo spallation events in the beamline materials, causing spallation product and neutron production. These neutrons are transported in LAHET until they escape the model or downscatter to an energy of $20 \mathrm{MeV}$.

Table 2. Thirteen regions in the CINDER'90 calculation. Volumes are in cubic centimeters.

\begin{tabular}{|c|c|c|c|c|}
\hline Region & Volume & SF & Material & Description \\
\hline tally 14 & $1.98 \mathrm{E}+09$ & a & mat 1 & Tunnel Air \\
\hline tally 24 & $1.04 \mathrm{E}+09$ & $\mathrm{~b}$ & mat 2 & Tunnel Concrete \\
\hline tally 44 & $1.38 E+06$ & c & mat 4 & B82 Magnet \\
\hline tally 54 & $4.27 \mathrm{E}+06$ & d & mat 5 & SS-316(m) \\
\hline tally 64 & $5.64 \mathrm{E}+05$ & e & mat 6 & Niobium \\
\hline tally 74 & $8.39 \mathrm{E}+05$ & $f$ & mat 7 & Liquefied Helium \\
\hline tally 84 & $9.18 \mathrm{E}+05$ & $\mathrm{~g}$ & mat 8 & Al 6061-T6 \\
\hline tally 94 & $5.48 \mathrm{E}+06$ & h & mat 9 & Water \\
\hline tally 104 & $1.44 \mathrm{E}+06$ & i & mat 10 & Carbon Steel \\
\hline tally 114 & $2.77 \mathrm{E}+05$ & $\mathbf{j}$ & mat 11 & Copper Heat Shield \\
\hline tally 124 & $1.17 \mathrm{E}+06$ & $\mathbf{k}$ & mat 12 & SS-316 (m12) \\
\hline tally 134 & $1.39 \mathrm{E}+05$ & 1 & mat 13 & Helium Gas \\
\hline tally 144 & $5.56 \mathrm{E}+05$ & $\underline{m}$ & mat 14 & $50-50$ Helium \\
\hline tally 154 & 1.39E+05 & n & mat 15 & Liquid Helium \\
\hline
\end{tabular}

Once a neutron's energy falls to $20 \mathrm{MeV}$ or below, its vital statistics are written to a source file for use by MCNP. MCNP will begin transport of the neutron preserving its energy, position, and direction, and will transport until the neutron escapes the system or reaches a predetermined cutoff energy. MCNP tallies a track-length estimate of the flux in the regions of interest for later input into CINDER'90. These flux tallies, calculated by MCNP, are time averaged over all cells in the tally regions containing the material of interest.

Figures 5 through 8 show flux maps of the accelerator tunnel region. ${ }^{15}$ These were done with special versions of MCNP and LAHET, which tally fluxes in rectangular arrays. Two 200×200 arrays were used for these tallies. For Figures 5 and 7, the array was parallel to the xz-plane at $y=0$, and extended $1 \mathrm{~m}$ above and below the beam centerline. For Figures 6 and 8 , the array was parallel to the $x y$-plane at $z=0$, and extended $1 \mathrm{~m}$ on each side of the $\mathrm{z}=0$ plane. The areas in which the highest fluxes occur are in the B82 magnets, where spallation neutron production is the primary source of neutrons in the accelerator tunnel. These magnets can be easily identified in both Figures 5 and 7 as the dark high-flux areas in the beamline. The two outer lines plot the inside edge of the tunnel and the two inner lines represent the outer limits of the cryostat vacuum vessel. In Figures 6 and 8, the outline of the tunnel walls, the wave-guide port, three water pipes, the outer wall of the cryostat vacuum vessel, and the outer wall of the copper heat shield have been added for reference. The streaming nature of the high-energy neutrons in Figures 5 and 6 can be contrasted with the almost homogeneous nature of the low-energy neutrons in Figures 7 and 8.

MCNP gives flux values normalized to the total number of source protons. This allows the flux to be scaled with the current of the proton beam. For this calculation, an estimate of $10 \mathrm{nA} / \mathrm{m}$ was used for the beam current loss during normal operations. An example of the flux values passed from MCNP to CINDER' 90 is shown in Table 3. Table 3 shows the flux values calculated by MCNP for all air-containing regions in the accelerator tunnel. The fluxes are calculated in 63-group format to correspond with the 63-group data libraries used by CINDER'90 in the calculation. Since MCNP has an energy limit of $20 \mathrm{MeV}$, the $20-25 \mathrm{MeV}$ energy group flux is zero. All data passed to CINDER' 90 for this group is passed in separate files from LAHET. A flux file for each of the thirteen regions of interest, shown in Table 2, is passed from MCNP to CINDER'90. 


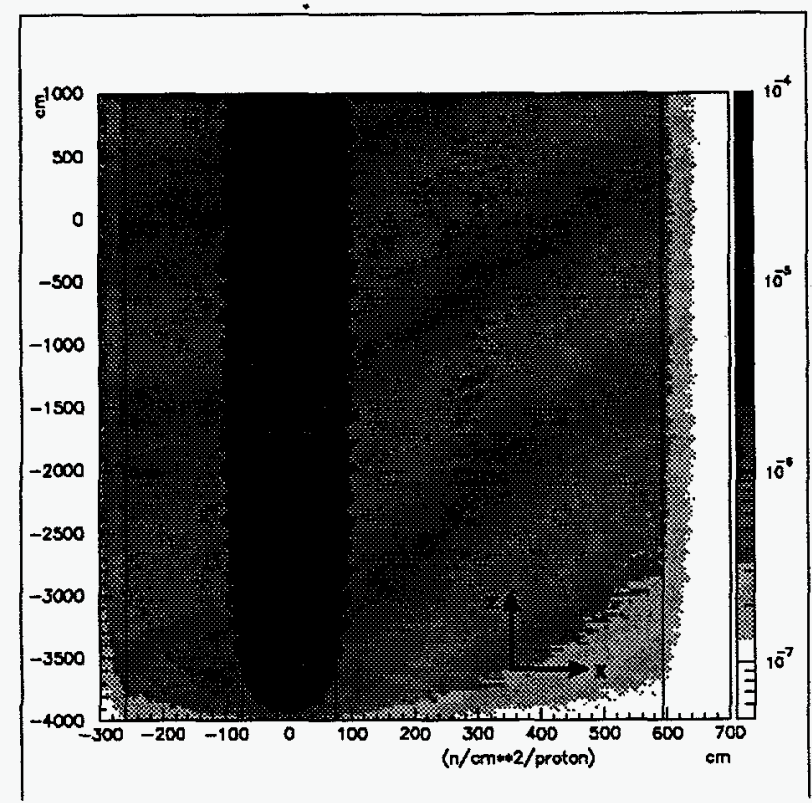

Figure 5. Neutron flux for energies above $20 \mathrm{MeV}$. The tally array extends $1 \mathrm{~m}$ above and below the beam centerline.

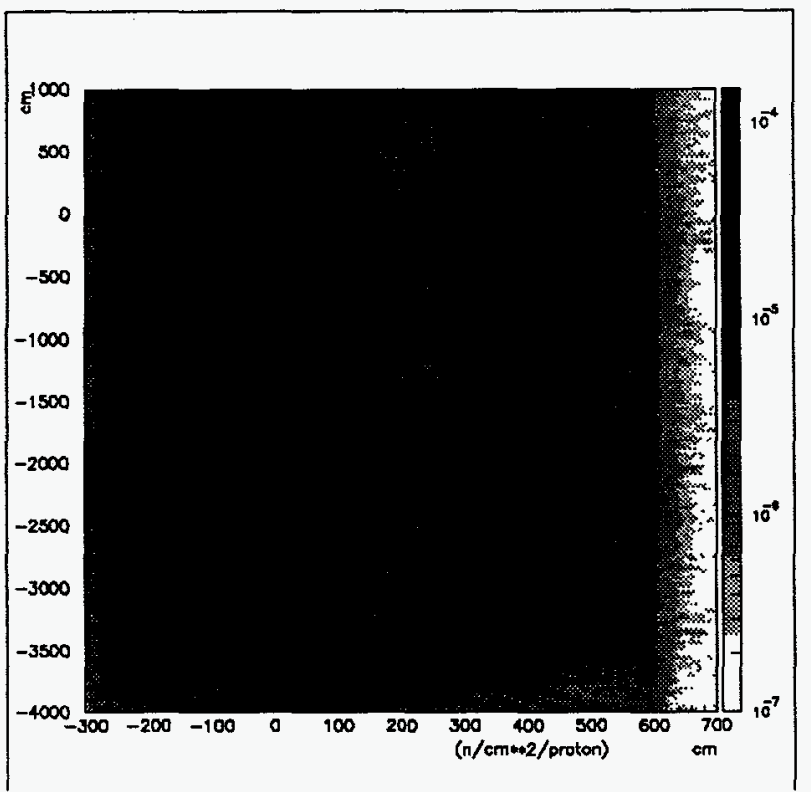

Figure 7. Neutron flux for energies below $20 \mathrm{MeV}$. The tally array extends $1 \mathrm{~m}$ above and below the beam centerline.

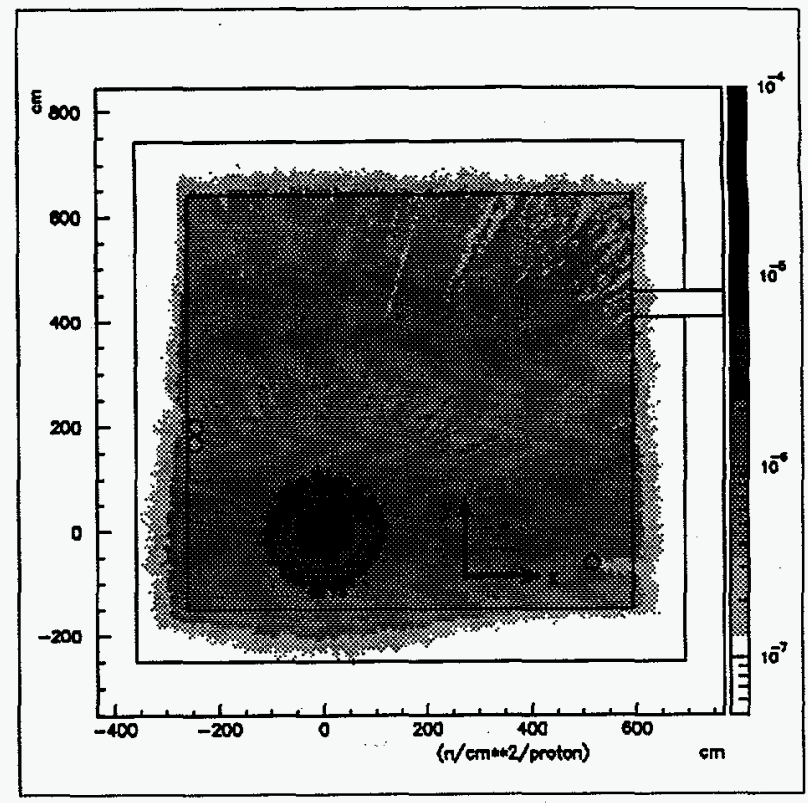

Figure 6. Neutron flux for energies above $20 \mathrm{MeV}$. Beam centerline is at $(0,0)$. The array tallies $1 \mathrm{~m}$ on each side of the $\mathrm{z}=0$ plane.

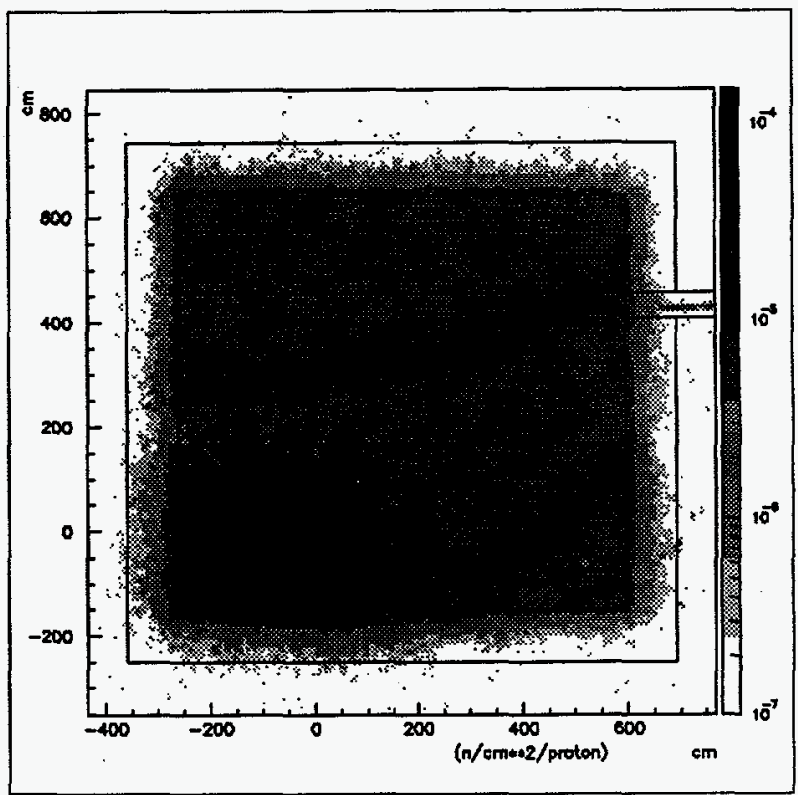

Figure 8. Neutron flux for energies below $20 \mathrm{MeV}$. Beam centerline is at $(0,0)$. The array tallies $1 \mathrm{~m}$ on each side of the $\mathrm{z}=0$ plane.

Irradiation and cooling times are input parameters to the CINDER' 90 code. For this calculation, two irradiation times are important. For the air activation calculation, the most conservative result would come from air activated for the full 9-month operation of the accelerator. To determine deactivation and decommissioning (D\&D) radiation levels for accelerator components, the full 40-year irradiation history is required. Therefore, a 9-month irradiation time was calculated, followed by several cooling times, up to three months, for air activation results. The irradiation then pro- 
ceeded for an additional 39 years to obtain the tunnel component activation results. For the remaining 39-year calculation, the irradiation was done using $75 \%$ of the normal operational beam current to allow for the $75 \%$ availability for operation each year. Cooling times from 1 second to 30,000 years were then calculated for the characterization of the D\&D radiation levels.

Table 3. 63-group flux values passed from MCNP to CINDER'90 for the interior tunnel air. The nuclide production for all reactions above $20 \mathrm{MeV}$ is calculated directly in LAHET, and therefore the flux value for this group is zero. Units for flux are per incident proton.

\begin{tabular}{|c|c|c|c|c|c|c|c|c|c|c|c|}
\hline $\begin{array}{l}\text { Energy } \\
(\mathrm{MeV})\end{array}$ & $\begin{array}{c}\text { Flux } \\
(\mathrm{n} / \mathrm{sq} \cdot \mathrm{cm} / \mathrm{s} / \mathrm{p})\end{array}$ & $\begin{array}{c}\text { Error } \\
(\%)\end{array}$ & $\begin{array}{l}\text { Energy } \\
\text { (MeV) }\end{array}$ & $\begin{array}{c}\text { Flux } \\
\text { (n/sq.cm/s/p) }\end{array}$ & $\begin{array}{c}\text { Error } \\
(\%)\end{array}$ & $\begin{array}{l}\text { Energy } \\
(\mathrm{MeV}) \\
\end{array}$ & $\begin{array}{c}\text { Flux } \\
(\mathrm{n} / \mathrm{sq}, \mathrm{cm} / \mathrm{s} / \mathrm{p})\end{array}$ & $\begin{array}{c}\text { Error } \\
(\%)\end{array}$ & $\begin{array}{l}\text { Energy } \\
(\mathrm{MeV})\end{array}$ & $\begin{array}{c}\text { Flux } \\
(\mathrm{n} / \mathrm{sq} . \mathrm{cm} / \mathrm{s} / \mathrm{p}) \\
\end{array}$ & $\begin{array}{c}\text { Error } \\
(\%)\end{array}$ \\
\hline $5.00 \mathrm{E}-09$ & 3.83E-09 & $1.92 \%$ & $6.83 \mathrm{E}-07$ & $1.81 \mathrm{E}-08$ & $1.28 \%$ & 2.04E-03 & $2.50 \mathrm{E}-08$ & $1.12 \%$ & $6.39 \mathrm{E}-01$ & $6.14 \mathrm{E}-08$ & $0.67 \%$ \\
\hline $1.00 \mathrm{E}-08$ & $1.01 \mathrm{E}-08$ & $1.23 \%$ & $1.13 \mathrm{E}-06$ & 1.71E-08 & $1.32 \%$ & $2.40 \mathrm{E}-03$ & $8.67 \mathrm{E}-09$ & $1.72 \%$ & $8.21 \mathrm{E}-01$ & $5.50 \mathrm{E}-08$ & $0.71 \%$ \\
\hline $1.50 \mathrm{E}-08$ & $1.59 \mathrm{E}-08$ & $1.01 \%$ & $1.86 \mathrm{E}-06$ & $1.71 \mathrm{E}-08$ & $1.31 \%$ & $2.84 \mathrm{E}-03$ & $7.21 \mathrm{E}-09$ & $1.86 \%$ & $1.11 \mathrm{E}+\infty 0$ & 4.67E-08 & $0.77 \%$ \\
\hline $2.00 \mathrm{E}-08$ & $1.76 \mathrm{E}-08$ & $0.96 \%$ & $3.06 \mathrm{E}-06$ & $1.71 \mathrm{E}-08$ & $1.33 \%$ & $3.36 \mathrm{E}-03$ & $7.23 \mathrm{E}-09$ & $1.87 \%$ & $1.35 \mathrm{E}+\infty 0$ & $2.84 \mathrm{E}-08$ & $0.95 \%$ \\
\hline $2.50 \mathrm{E}-08$ & 2.13E- -08 & $0.88 \%$ & $5.04 \mathrm{E}-06$ & $1.74 \mathrm{E}-08$ & $1.31 \%$ & 5.53E-03 & $2.53 \mathrm{E}-08$ & $1.11 \%$ & $1.74 \mathrm{E}+00$ & 2.94E-08 & $0.95 \%$ \\
\hline $3.00 \mathrm{E}-08$ & $2.02 \mathrm{E}-08$ & $0.89 \%$ & $8.32 \mathrm{E}-06$ & $1.75 \mathrm{E}-08$ & $1.32 \%$ & $9.12 \mathrm{E}-03$ & $2.64 \mathrm{E}-08$ & $1.11 \%$ & $2.23 \mathrm{E}+\infty 0$ & 2.44E-08 & $1.02 \%$ \\
\hline 3.50E-08 & 2.08E-08 & $0.88 \%$ & 1.37E-05 & $1.79 \mathrm{E}-08$ & $1.31 \%$ & $1.50 \mathrm{E}-02$ & 2.94E-08 & $1.04 \%$ & $2.87 \mathrm{E}+00$ & 2.46E-08 & $1.03 \%$ \\
\hline 4.20E-08 & $2.85 \mathrm{E}-08$ & $0.79 \%$ & 2.26E-05 & $1.81 E-08$ & $1.30 \%$ & $1.99 \mathrm{E}-02$ & $1.86 \mathrm{E}-08$ & $1.24 \%$ & $3.68 \mathrm{E}+00$ & 1.72E-08 & $1.17 \%$ \\
\hline $5.00 \mathrm{E}-08$ & 3.03E-08 & $0.76 \%$ & 3.73E-05 & $1.84 \mathrm{E}-08$ & $1.29 \%$ & 2.55E-02 & 2.11E-08 & $1.12 \%$ & $4.97 \mathrm{E}+00$ & $1.61 \mathrm{E}-08$ & $1.19 \%$ \\
\hline $5.80 \mathrm{E}-08$ & $2.70 \mathrm{E}-08$ & $0.81 \%$ & $6.14 \mathrm{E}-05$ & $1.89 \mathrm{E}-08$ & $1.27 \%$ & $4.09 \mathrm{E}-02$ & $3.23 \mathrm{E}-08$ & $0.99 \%$ & $6.07 \mathrm{E}+00$ & $9.14 \mathrm{E}-09$ & $1.51 \%$ \\
\hline $6.70 \mathrm{E}-08$ & $2.61 \mathrm{E}-08$ & $0.83 \%$ & $1.01 \mathrm{E}-04$ & $1.95 \mathrm{E}-08$ & $1.26 \%$ & $6.74 \mathrm{E}-02$ & 4.54E-08 & $0.85 \%$ & $1.00 \mathrm{E}+01$ & $2.00 \mathrm{E}-0.8$ & $1.04 \%$ \\
\hline $8.00 \mathrm{E}-08$ & 3.01E-08 & $0.80 \%$ & $1.67 \mathrm{E}-04$ & 2.05E-08 & $1.23 \%$ & $1.11 \mathrm{E}-01$ & $5.80 \mathrm{E}-08$ & $0.75 \%$ & $1.49 \mathrm{E}+01$ & 1.39E-08 & $1.21 \%$ \\
\hline $1.00 \mathrm{E}-07$ & $3.40 \mathrm{E}-08$ & $0.77 \%$ & 2.75E-04 & 2.07E-08 & $1.21 \%$ & $1.83 \mathrm{E}-01$ & 8.90E-08 & $0.62 \%$ & 1.69E+01 & $3.78 \mathrm{E}-09$ & $2.25 \%$ \\
\hline $1.52 \mathrm{E}-07$ & $4.22 \mathrm{E}-08$ & $0.77 \%$ & 4.54E-04 & 2.02E-08 & $1.23 \%$ & $3.02 \mathrm{E}-01$ & $1.03 \mathrm{E}-07$ & $0.59 \%$ & $2.00 \mathrm{E}+01$ & 4.37E-09 & $2.11 \%$ \\
\hline 2.51E-07 & 2.55E-08 & $1.04 \%$ & $7.49 E-04$ & 2.17E-08 & $1.19 \%$ & $3.89 \mathrm{E}-01$ & $5.76 \mathrm{E}-08$ & $0.68 \%$ & $2.50 \mathrm{E}+01$ & $0.00 \mathrm{E}+00$ & $0.00 \%$ \\
\hline 4.14E-07 & $1.84 E-08$ & $1.26 \%$ & $1.23 \mathrm{E}-03$ & $2.22 \mathrm{E}-0.8$ & $1.18 \%$ & 4.98E-01 & $4.24 \mathrm{E}-08$ & $0.80 \%$ & total & $1.62 \mathrm{E}-06$ & $0.27 \%$ \\
\hline
\end{tabular}

\section{RESULTS}

The CINDER' 90 output provides a variety of data in tabular form. Atom and activity densities are calculated, as well as total mass and total activity. Decay power, power densities, fission densities, and fission power densities can also be calculated for reactor problems. In addition, dilution factor tables are created for the nuclide products calculated.

The fourth table created by CINDER' 90 is the total activity, by nuclide, in Curies, in the tunnel air. Only the tally14 region fluxes (regions in the model containing air only) were used by CINDER' 90 for the calculation. Table 4 lists the top 20 nuclides, in descending order of activity in Curies, after a nine-month irradiation. At the bottom of Table 4 is the total activity of all contributing nuclides (including the top 20) in the tunnel air, after the nine-month irradiation. Also shown are some subsequent cooling times. The values calculated by CINDER' 90 are normalized per unit volume of air, so the results shown in Table 4 are for the entire air volume in the accelerator tunnel, approximately $6.6 \times 10^{10} \mathrm{cc}$ for the $1-\mathrm{km}$ tunnel length. The total activity, over the $1-\mathrm{km}$ long accelerator tunnel, is less than $5 \mathrm{Ci}$. This number is conservative, due to the assumption that the beam remains at an energy of $1700 \mathrm{MeV}$ throughout the entire tunnel length. The average beam energy throughout the tunnel will be much less. Total activity falls to less that one Curie after one hour of decay time. The largest contributor to activation in the tunnel air is ${ }^{13} \mathrm{~N}$, followed by ${ }^{41} \mathrm{Ar}$ and ${ }^{15} \mathrm{O}$.

With the exception of the regions containing helium, the remaining interior tunnel regions were combined to calculate the activity of the beamline components after the proposed 40-year lifetime of the accelerator. Table 5 lists the 20 largest contributors to the activity of the beamline components. These are listed in decreasing order, by total activity, after a 40-year irradiation (39 additional years after the initial 9-month irradiation). The largest D\&D problem resides in the B82 magnets, as evidenced by the highest activity nuclide, ${ }^{55} \mathrm{Fe}$, from the iron core of the super-conducting magnets. These are the areas that possessed the highest fluxes shown in Figures 5 through 8 . The total activation for the tunnel components was calculated to be almost $4 \mathrm{kCi}$. But since this calculation is for the entire $1-\mathrm{km}$ accelerator tunnel, the average activation is actually less than $4 \mathrm{Ci}$ per meter of tunnel. Table 6 shows the activity density and total activity for the regions in the model. The highest activity levels occur in the tunnel concrete, B82 magnets, and the stainless in the cryostat vacuum vessel. After a 10-day decay period, the concrete is reduced to manageable levels, leaving the magnets and cryostat vessels as the main D\&D waste problem. Again, due to beam energy assumptions, these are conservative numbers. Several other cooling times were calculated, but have not been included in Table 5 or 6 . 
Table 4. Twenty nuclides possessing the highest activity in the tunnel air after a nine-month irradiation, and their respective activities after several decay periods. The activities are in Curies, and are for the entire tunnel air volume. The totals are for the entire list of nuclides, and not just for the highest twenty.

\begin{tabular}{|c|c|c|c|c|c|c|c|c|c|c|c|}
\hline & & Irr. Time & \multicolumn{9}{|c|}{ Cooling Time } \\
\hline Nuclide & Halflife,(s) & $9 \mathrm{mon}$ & 1 sec & $3 \sec$ & 10 sec & $1 \mathrm{~min}$ & $3 \mathrm{~min}$ & $10 \mathrm{~min}$ & 1 hour & 3 hours & 10 hours \\
\hline N 13 & $5.98 \mathrm{E}+02$ & $1.28 \mathrm{E}+00$ & $1.27 \mathrm{E}+00$ & $1.27 \mathrm{E}+00$ & $1.26 \mathrm{E}+00$ & $1.19 E+00$ & $1.04 \mathrm{E}+00$ & $6.37 \mathrm{E}-01$ & $1.97 \mathrm{E}-02$ & $4.66 \mathrm{E}-06$ & $9.57 \mathrm{E}-19$ \\
\hline Ar 41 & $6.58 E+03$ & 4.58E-01 & $4.58 \mathrm{E}-01$ & 4.58E-01 & $4.57 \mathrm{E}-01$ & $4.55 \mathrm{E}-01$ & $4.49 \mathrm{E}-01$ & $4.30 \mathrm{E}-01$ & 3.13E-01 & $1.47 \mathrm{E}-01$ & $1.03 \mathrm{E}-02$ \\
\hline O 15 & $1.22 \mathrm{E}+02$ & $4.43 \mathrm{E}-01$ & $4.41 \mathrm{E}-01$ & $4.36 \mathrm{E}-01$ & $4.19 \mathrm{E}-01$ & $3.15 \mathrm{E}-01$ & $1.60 \mathrm{E}-01$ & $1.48 \mathrm{E}-02$ & $6.04 \mathrm{E}-10$ & $1.12 \mathrm{E}-27$ & \\
\hline B 12 & $2.02 \mathrm{E}-02$ & $3.51 \mathrm{E}-01$ & $5.09 \mathrm{E}-14$ & $7.98 \mathrm{E}-44$ & & & & & & & \\
\hline C 11 & $1.22 \mathrm{E}+03$ & $3.21 \mathrm{E}-01$ & $3.21 \mathrm{E}-01$ & $3.20 \mathrm{E}-01$ & $3.19 E-01$ & $3.10 \mathrm{E}-01$ & $2.90 \mathrm{E}-01$ & $2.28 \mathrm{E}-01$ & $4.17 \mathrm{E}-02$ & $7.05 \mathrm{E}-04$ & $4.43 \mathrm{E}-10$ \\
\hline N 16 & $7.13 \mathrm{E}+00$ & $2.90 \mathrm{E}-01$ & $2.63 \mathrm{E}-01$ & $2.16 \mathrm{E}-01$ & $1.10 \mathrm{E}-01$ & $8.48 \mathrm{E}-04$ & $7.28 \mathrm{E}-09$ & $1.35 \mathrm{E}-26$ & & & \\
\hline O 14 & $7.06 \mathrm{E}+01$ & 2.27E-01 & $2.25 \mathrm{E}-01$ & $2.20 \mathrm{E}-01$ & $2.06 \mathrm{E}-01$ & $1.26 \mathrm{E}-01$ & $3.87 E-02$ & $6.27 \mathrm{E}-04$ & $1.01 \mathrm{E}-16$ & & \\
\hline Be 8 & $7.00 \mathrm{E}-17$ & $1.85 \mathrm{E}-01$ & $6.50 \mathrm{E}-03$ & $1.03 \mathrm{E}-03$ & $1.88 \mathrm{E}-06$ & & & & & & \\
\hline C 10 & $1.93 E+01$ & $1.72 \mathrm{E}-01$ & $1.66 \mathrm{E}-01$ & $1.54 \mathrm{E}-01$ & $1.20 \mathrm{E}-01$ & $1.98 \mathrm{E}-02$ & $2.64 \mathrm{E}-04$ & $7.20 \mathrm{E}-11$ & & & \\
\hline B 13 & $1.74 \mathrm{E}-02$ & $1.65 \mathrm{E}-01$ & 8.28E-19 & $2.07 E-53$ & $1.63 \mathrm{E}-174$ & & & & & & \\
\hline N 12 & $1.10 \mathrm{E}-02$ & $1.55 \mathrm{E}-01$ & 6.67E-29 & & & & & & & & \\
\hline B 9 & $8.00 \mathrm{E}-19$ & $8.91 \mathrm{E}-02$ & 8.53E-05 & $1.48 \mathrm{E}-09$ & & & & & & & \\
\hline N 11 & $1.00 \mathrm{E}-21$ & $7.81 \mathrm{E}-02$ & & & & & & & & & \\
\hline Be 11 & $1.38 \mathrm{E}+01$ & $6.56 \mathrm{E}-02$ & $6.24 \mathrm{E}-02$ & $5.65 \mathrm{E}-02$ & $3.97 \mathrm{E}-02$ & $3.23 \mathrm{E}-03$ & $7.82 \mathrm{E}-06$ & $5.47 \mathrm{E}-15$ & $2.21 \mathrm{E}-80$ & & \\
\hline Li 5 & $3.00 \mathrm{E}-22$ & $4.76 \mathrm{E}-02$ & & & & & & & & & \\
\hline $\mathrm{Be} 6$ & $5.00 \mathrm{E}-21$ & $4.46 \mathrm{E}-02$ & & & & & & & & & \\
\hline C 14 & $1.81 \mathrm{E}+11$ & $3.83 \mathrm{E}-02$ & $3.83 \mathrm{E}-02$ & $3.83 \mathrm{E}-02$ & $3.83 \mathrm{E}-02$ & $3.83 \mathrm{E}-02$ & $3.83 \mathrm{E}-02$ & $3.83 \mathrm{E}-02$ & $3.83 \mathrm{E}-02$ & $3.83 \mathrm{E}-02$ & $3.83 \mathrm{E}-02$ \\
\hline B 7 & $4.00 \mathrm{E}-22$ & $3.54 \mathrm{E}-02$ & & & & & & & & & \\
\hline $\mathrm{Li} 8$ & $8.38 \mathrm{E}-01$ & $3.13 E-02$ & $1.43 \mathrm{E}-02$ & $2.73 \mathrm{E}-03$ & 8.34E-06 & 9.12E-24 & & & & & \\
\hline Be 12 & $2.40 \mathrm{E}-02$ & $2.80 \mathrm{E}-02$ & $8.03 E-15$ & & & & & & & & \\
\hline Total & & $4.77 \mathrm{E}+00$ & $3.35 E+\infty 0$ & $3.23 E+00$ & $3.02 E+00$ & $2.50 \mathrm{E}+00$ & $2.05 E+00$ & $1.39 \mathrm{E}+00$ & $4.55 \mathrm{E}-01$ & 2.27E-01 & $8.98 \mathrm{E}-02$ \\
\hline
\end{tabular}

Table 5. Twenty nuclides possessing the highest activity in the metal beamline components after a 40-year irradiation, and their respective activities after several decay periods. The activities are in Curies, and are for the entire accelerator length of $1 \mathrm{~km}$. The totals are for the entire list of nuclides, and not just for the highest twenty.

\begin{tabular}{|c|c|c|c|c|c|c|c|c|c|c|c|}
\hline \multirow[b]{2}{*}{ Nuclide } & \multirow[b]{2}{*}{ Half-life (s) } & \multicolumn{5}{|c|}{ Cooling Time } & Irr. Time & \multicolumn{4}{|c|}{ Cooline Time } \\
\hline & & $1 \mathrm{day}$ & 3 days & 10 days & $1 \mathrm{mon}$ & $3 \mathrm{mon}$ & 39 vears & 1 day & 1 vear & 10 vears & 100 vears \\
\hline $\mathrm{Fe} 55$ & $8.62 \mathrm{E}+07$ & $1.03 \mathrm{E}+02$ & $1.03 \mathrm{E}+02$ & $1.03 \mathrm{E}+02$ & $1.01 \mathrm{E}+02$ & $9.50 \mathrm{E}+01$ & $4.47 \bar{E}+02$ & $4.47 \mathrm{E}+02$ & $3.40 \mathrm{E}+02$ & $3.46 \mathrm{E}+01$ & $1.89 \mathrm{E}-08$ \\
\hline $\operatorname{Mn} 56$ & $9.28 \mathrm{E}+03$ & $6.47 \mathrm{E}-01$ & $1.61 E-06$ & $3.92 \mathrm{E}-26$ & & & $3.07 E+02$ & $4.85 \mathrm{E}-01$ & & & \\
\hline Al 28 & $1.34 \mathrm{E}+02$ & $4.96 \mathrm{E}-01$ & $1.01 E-01$ & $3.86 \mathrm{E}-04$ & 3.35E-11 & & $3.06 \mathrm{E}+02$ & $3.73 \mathrm{E}-01$ & & & \\
\hline $\mathrm{Na} 24$ & $5.28 \mathrm{E}+04$ & $9.33 E+01$ & $9.64 \mathrm{E}+00$ & $3.42 \mathrm{E}-03$ & $2.90 \mathrm{E}-13$ & & $2.18 E+02$ & $7.00 \mathrm{E}+01$ & & & \\
\hline Mn 54 & $2.70 \mathrm{E}+07$ & $1.23 \mathrm{E}+02$ & $1.22 \mathrm{E}+02$ & $1.20 \mathrm{E}+02$ & $1.15 \mathrm{E}+02$ & $9.38 \mathrm{E}+01$ & $2.02 \mathrm{E}+02$ & $2.02 \mathrm{E}+02$ & $8.40 \mathrm{E}+01$ & $5.68 \mathrm{E}-02$ & $3.77 \mathrm{E}-47$ \\
\hline $\mathrm{Na} 24^{*}$ & $2.02 \mathrm{E}-02$ & & & & & & $1.57 \mathrm{E}+02$ & & & & \\
\hline H 3 & $3.89 \mathrm{E}+08$ & $9.32 \mathrm{E}+00$ & $9.31 E+00$ & $9.30 \mathrm{E}+00$ & $9.28 \mathrm{E}+00$ & $9.15 E+00$ & $1.51 \mathrm{E}+02$ & $1.51 E+02$ & $1.43 E+02$ & $8.59 E+01$ & $7.64 \mathrm{E}-01$ \\
\hline Cr 51 & $2.39 \mathrm{E}+06$ & $1.72 \mathrm{E}+02$ & $1.64 \mathrm{E}+02$ & $1.37 \mathrm{E}+02$ & $8.25 \mathrm{E}+01$ & $8.39 \mathrm{E}+00$ & $1.33 \mathrm{E}+02$ & $1.29 \mathrm{E}+02$ & $6.65 \mathrm{E}-03$ & & \\
\hline O 15 & $1.22 \mathrm{E}+02$ & & & & & & $6.93 \mathrm{E}+01$ & & & & \\
\hline $\operatorname{Co} 57$ & $2.35 \mathrm{E}+07$ & 4.52E+01 & $4.51 \mathrm{E}+01$ & $4.43 E+01$ & $4.20 \mathrm{E}+01$ & $3.33 \mathrm{E}+01$ & $6.77 \mathrm{E}+01$ & $6.76 \mathrm{E}+01$ & $2.47 \mathrm{E}+01$ & $5.65 \mathrm{E}-03$ & $3.74 \mathrm{E}-37$ \\
\hline $\operatorname{Co} 58$ & $6.13 E+06$ & $7.85 \mathrm{E}+01$ & $7.70 E+01$ & $7.20 \mathrm{E}+01$ & $5.89 \mathrm{E}+01$ & $2.41 E+01$ & $6.38 \mathrm{E}+01$ & $6.33 \mathrm{E}+01$ & $1.34 \mathrm{E}+00$ & $1.49 \mathrm{E}-14$ & \\
\hline $\mathrm{Cu} 64$ & $4.57 E+04$ & $2.18 \mathrm{E}+01$ & $1.59 \mathrm{E}+00$ & $1.66 \mathrm{E}-04$ & $3.93 \mathrm{E}-16$ & & $6.06 \mathrm{E}+01$ & $1.64 \mathrm{E}+01$ & & & \\
\hline Mn 52 & $4.83 E+05$ & $6.85 \mathrm{E}+01$ & $5.36 \mathrm{E}+01$ & $2.25 \mathrm{E}+01$ & $1.79 \mathrm{E}+00$ & 2.17E-05 & $5.75 \mathrm{E}+01$ & $5.14 \mathrm{E}+01$ & $2.91 \mathrm{E}-20$ & & \\
\hline V 49 & $2.92 \mathrm{E}+07$ & $3.22 \mathrm{E}+01$ & $3.21 \mathrm{E}+01$ & $3.16 \mathrm{E}+01$ & $3.03 \mathrm{E}+01$ & $2.51 \mathrm{E}+01$ & $5.63 \mathrm{E}+01$ & $5.62 \mathrm{E}+01$ & $2.50 \mathrm{E}+01$ & $2.96 \mathrm{E}-02$ & $1.40 \mathrm{E}-29$ \\
\hline V 52 & $2.25 \mathrm{E}+02$ & & & & & & $4.78 \mathrm{E}+01$ & & & & \\
\hline Co 56 & $6.80 \mathrm{E}+06$ & $5.30 \mathrm{E}+01$ & $5.22 \mathrm{E}+01$ & $4.93 \mathrm{E}+01$ & $4.13 E+01$ & $1.85 \mathrm{E}+01$ & $4.41 \mathrm{E}+01$ & $4.38 \mathrm{E}+01$ & $1.37 \mathrm{E}+00$ & $3.73 \mathrm{E}-13$ & \\
\hline N 16 & $7.13 E+00$ & & & & & & $4.25 \mathrm{E}+01$ & & & & \\
\hline Ar 37 & $3.03 E+06$ & $5.06 \mathrm{E}+01$ & $4.86 \mathrm{E}+01$ & $4.23 E+01$ & $2.83 \mathrm{E}+01$ & $4.64 \mathrm{E}+00$ & $3.89 \mathrm{E}+01$ & $3.81 E+01$ & $1.55 \mathrm{E}-02$ & & \\
\hline $\mathrm{Fe} 53$ & $5.11 E+02$ & & & & & & $3.64 \mathrm{E}+01$ & & & & \\
\hline V 48 & $1.38 \mathrm{E}+06$ & $4.35 \mathrm{E}+01$ & $4.01 \mathrm{E}+01$ & $2.96 \mathrm{E}+01$ & $1.22 \mathrm{E}+01$ & $2.32 \mathrm{E}-01$ & $3.38 \mathrm{E}+01$ & $3.26 \mathrm{E}+01$ & $1.20 \mathrm{E}-06$ & $1.36 \mathrm{E}-68$ & \\
\hline Total & & $1.22 \mathrm{E}+03$ & $9.91 \mathrm{E}+02$ & $8.18 \mathrm{E}+02$ & $6.29 \mathrm{E}+02$ & $3.65 \mathrm{E}+02$ & $3.58 \mathrm{E}+03$ & $1.69 E+03$ & $6.84 E+02$ & $1.54 \mathrm{E}+02$ & $9.72 E+00$ \\
\hline
\end{tabular}


Table 6. Activity density and total activity of the accelerator beamline components after a 40-year irradiation, and after a 10 day decay period. Volumes are scaled to the entire 1-km length of the accelerator, and activity is for the total 1-km length.

\begin{tabular}{|c|c|c|c|c|c|}
\hline Region & $\begin{array}{l}\text { Volume } \\
\text { (cc) }\end{array}$ & Description & $\begin{array}{l}\text { Activity Density } \\
\text { (Ci/cc) }\end{array}$ & $\begin{array}{c}\text { Total Activity } \\
\text { (Ci) }\end{array}$ & $\begin{array}{l}10 \text { Days Later } \\
\text { (Ci) }\end{array}$ \\
\hline tally 14 & $6.59 \mathrm{E}+10$ & Tunnel Air & - & - & - \\
\hline tally 24 & $3.48 \mathrm{E}+10$ & Tunnel Concrete & $3.02 \mathrm{E}-08$ & 1052.86 & 66.95 \\
\hline tally 44 & $4.60 \mathrm{E}+07$ & B82 Magnet & $2.41 \mathrm{E}-05$ & 1106.34 & 602.96 \\
\hline tally 54 & $1.42 E+08$ & SS-316 (Cryostat Vacuum Vessel, beamline) & 7.13E-06 & 1014.99 & 550.37 \\
\hline tally 64 & $1.88 \mathrm{E}+07$ & Niobium & $1.43 E-05$ & 269.15 & 137.50 \\
\hline tally 74 & $2.80 \mathrm{E}+07$ & Liquefied Helium & - & - & - \\
\hline tally 84 & $3.06 \mathrm{E}+07$ & Al 6061-T6 (Waveguide) & $6.28 \mathrm{E}-07$ & 19.21 & 0.12 \\
\hline tally 94 & $1.83 E+08$ & Water & $1.95 \mathrm{E}-08$ & 3.56 & 0.01 \\
\hline tally104 & $4.79 \mathrm{E}+07$ & Carbon Steel (Waveguide Support Structure) & $5.84 \mathrm{E}-07$ & 27.95 & 14.03 \\
\hline tally114 & $9.23 \mathrm{E}+06$ & Copper Heat Shield & $1.12 \mathrm{E}-05$ & 103.76 & 10.53 \\
\hline tally124 & $3.89 \mathrm{E}+07$ & SS-316 (Accelerator Cavity Stainless) & 4.10E-07 & 15.93 & 9.42 \\
\hline tally134 & $4.63 E+06$ & Helium Gas & - & - & - \\
\hline tally144 & $1.85 E+07$ & 50-50 Helium & - & - & - \\
\hline tally 154 & $4.63 E+06$ & Liquid Helium & - & - & - \\
\hline
\end{tabular}

\section{CONCLUSIONS}

CINDER'90, in conjunction with the LCS, provides an excellent method for calculating nuclide production, activation, and decay. Complete activation calculations have been done for the tunnel air inside the 1700-MeV APT accelerator, with time-dependent results obtained for a 9-month irradiation and including decay periods from 1 second to 3 months afterwards. The total activation of the accelerator beamline components was also calculated for the lifetime of the accelerator for the deactivation and decommissioning of the APT accelerator. The source terms produced through the LCS/CINDER' 90 combination of codes can then be used in a variety of calculations, such as personnel dose calculations and safety calculations, needed for such documentation as the Environmental Impact Statement, and the ultimate safe operation of the APT 1700$\mathrm{MeV}$ accelerator.

\section{REFERENCES}

1. R. E. Prael and H. Lichtenstein, "User Guide to LCS: The LAHET Code System," Los Alamos National Laboratory report LA-UR-89-3014 (September 1989).

2. W.B. Wilson, et al., "Accelerator Transmutation Studies at Los Alamos with LAHET, MCNP, and CINDER'90," Proceedings of the Workshop on Simulation of Accelerator Radiation Environments, January 11-15, 1993, Santa Fe, New Mexico; Los Alamos National Laboratory conference proceedings LA-12835-C (October 1994) pp. 115-133; also available as Los Alamos National Laboratory informal document LA-UR-93-3080 (January 11, 1993).

3. W.B. Wilson, T.R. England, D.C. George, D.W. Muir, and P.G. Young, "Recent Development of the CINDER' 90 Transmutation Code and Data Library for Actinide Transmutation Studies," Proceedings of the GLOBAL'95 International Conference on Evaluation of Emerging Nuclear Fuel Cycle Systems, Versailles, France, September 11-14, 1995, pp.848854; Los Alamos National Laboratory preprint LA-UR-95-2181.

4. J. F. Briesmeister, Ed., "MCNP - A General Monte Carlo N-Particle Transport Code," Los Alamos National Laboratory report LA-12625-M, Version 4B, (March 1997).

5. Radiation Shielding Information Center, "HETC Monte Carlo High-Energy Nucleon-Meson Transport Code," Oak Ridge National Laboratory report CCC 178 (August 1977). 
6. H. W. Bertini, "Intranuclear-Cascade Calculation of the Secondary Nucleon Spectra from Nucleon-Nucleus Interactions in the Energy Range 340 to $2900 \mathrm{MeV}$ and Comparisons with Experiment," Phys. Rev. 188, 1711 (1969).

7. R. E. Prael and M. Bozoian, "Adaptation of the Multistage Preequilibrium Model for the Monte Carlo Method (I)," Los Alamos National Laboratory report LA-UR-88-3238 (September 1988); R. E. Prael and M. Bozoian, "Adaptation of the Multistage Preequilibrium Model for the Monte Carlo Method (II)," Los Alamos National Laboratory (to be pub.).

8. L. Dresner, "EVAP-A FORTRAN Program for Calculating the Evaporation of Various Particles from Excited Compound Nuclei," Oak Ridge National Laboratory report ORNL-TM-96 (April 1962).

9. K. Chen, et al., "VEGAS: A Monte Carlo Simulation of Intranuclear Cascades," Phys Rev. 166, 949 (1968).

10. R. E. Prael and D.G. Madland, "LAHET Code System Modifications for LAHET2.8," Los Alamos National Laboratory report LA-UR-95-3605 (September 1995).

11. T.R. England, "CINDER -A One Point Depletion and Fission Product Program," Bettis Atomic Power Laboratory report WAPD-TM-334 (August 1962; Rev. June 1964).

12. T.R. England, R. Wilczynski, and N.L. Whittemore, "Cinder-7: An Interim Users Report," Los Alamos Scientific Laboratory report LA-5885-MS (April 1975).

13. W.B. Wilson, T.R. England, R.J. LaBauve, M.E. Battat, D.E. Wessol, and R.T. Perry, "CINDER-3: Depletion Code for Class VI Computers," Trans. Am. Nucl. Soc. 46, 724, (1984).

14. F.M. Mann, "REAC-2: A Users Manual and Code Description," Westinghouse Hanford Company report WHC-EP0282 (December 1989).

15. E.C. Snow, APT design calculations, Phase I., Bechtel Nevada Interoffice Memorandum No. F28D-ES-97-129, July 1997. 